\title{
A STUDY OF SUCCESS RATE OF BUTTERFLY TECHNIQUE
}

\author{
Yennie Rahmawati ${ }^{1}$, Siti Mina Tamah ${ }^{2}$
}

${ }^{1}$ Faculty of Medicine, Airlangga University, Surabaya, Indonesia

${ }^{2}$ Faculty of Medicine, Padjadjaran University, Bandung, Indonesia

*Corresponding Author: Yennie Rahmawati

Article Received: 12-06-19

Accepted: 20-10-19

Published: 05-11-19

Licensing Details: Author retains the right of this article. The article is distributed under the terms of the $\begin{array}{lllll}\text { Creative } & \text { Commons } & \text { Attribution-NonCommercial } & 4.0 & \text { License }\end{array}$ (http://www.creativecommons.org/licences/by-nc/4.0/) which permits non-commercial use, reproduction and distribution of the work without further permission provided the original work is attributed as specified on the Journal open access page

\section{ABSTRACT}

The use of Tympanoplasty as a remedy for minor perforations is a common trend these days. The technique is in use even from ancient time utilizing those day tools. Common criticism on this technique is that it bring disadvantages such as hospital stay, increased morbidity, and postoperative scar. Therefore, there was requirement to bring a more comprehensive technique. In this study, our objective is to assess the clinical and audiometric success rate of new tragal cartilage plug or butterfly technique tympanoplasty. The study is based on 30 patients who were in age category of 16 to 55 years of age. The results shows that out of 30 patients, 27 patients were based on graft taken up; while, the rest of the 3 patients showed residual perforation with an overall success rate of $90 \%$. The anatomical success was assessed by otoscopy with graft well set in place. The functional success was analyzed by audiogram, which showed decrease in AirBone (A-B) gap in 25 patients $(83.3 \%)$. Our conclusion is that the tympanoplasty method may be considered as an alternative treatment option for repair of tympanic membrane perforations.

Keywords: Tympanoplasty, Butterfly Technique, Tragal cartilage.

\section{INTRODUCTION}

Initially Zollner [1] and Wullstein [2] described major types of tympanic membrane perforation and since then, it remains a debated topic. The procedure of surgically repair comes with many variations based on different graft materials which are used from fat or adipose tissue, tragal, or 
conchal cartilage and or perichondrium to using the most common material like temporalis fascia. Interlay, overlay, and underlay are also major variations in this technique.

The technique remains successful, however, it comes with some disadvantages. One disadvantage is that it requires elevation of the tympanomeatal flap which increases the morbidity of the procedure and the degree of post-operative care. It also include the role of transcanal tragal cartilage plug tympanoplasty using Evaey's butterfly technique [4]. The benefit of using this technique is that it bypass the need for elevating a tympanomeatal flap and hence major drawbacks such as increased hospital stay, bleeding, pain, and morbidity are decreased. The stiffness of the cartilage and its locking edges provide the graft considerably stability.

In this study, the focus is to judge this new technique on the basis of its anatomical success as determine by the rate of complete perforation closure and also its functional as measured by post-operative hearing improvement through audiometry. Comparison will also be made with results based on tympanoplasties done with other graft materials.

\section{MATERIAL AND METHODS}

The study is a one year based prospective study conducted in one of the hospital with the aim to analyze the results of endoscopic trans canal 'cartilage plug or butterfly' underlay cartilage tympanoplasty technique performed in patients with small to medium sized central tympanic membrane perforations. The inclusion criteria is as follows;

presence of single or double quadrant small to medium sized central perforation with possibility to visualize all its borders, 3 months based dry ear, absence of a cholesteatoma, age range between 16 to 25, and air-bone gap (ABG) in the preoperative audiogram with no sensorineural loss. Based on the inclusion criteria, we included 30 patients.

All the patients who were assessed through a thorough general and otorhinolaryngological examination, audiometry, CT scan as required and preoperative tests. The results were evaluated based upon the perforation closure, post-operative hearing improvement checked by means of audiometry tests at 3 months, 6 months, and presence of any post-operative complications. We continued follow up for 6 months of postoperative period. The analysis was based on Chi-square with correction by Fischer's exact test.

\section{Technique}

General anesthesia was administered before performing the surgery in most cases in order to main an uniformity and also as a day care case. The perforation edges were visualized with a $0^{\circ}$, $2.7 \mathrm{~mm}$ rigid otoendoscope. Angled pick was used for freshening the edges of the perforation. Methylene blue solution was used for measuring the size of the perforation along with the edges of margins of the perforation using a Jobson Horne probe. 


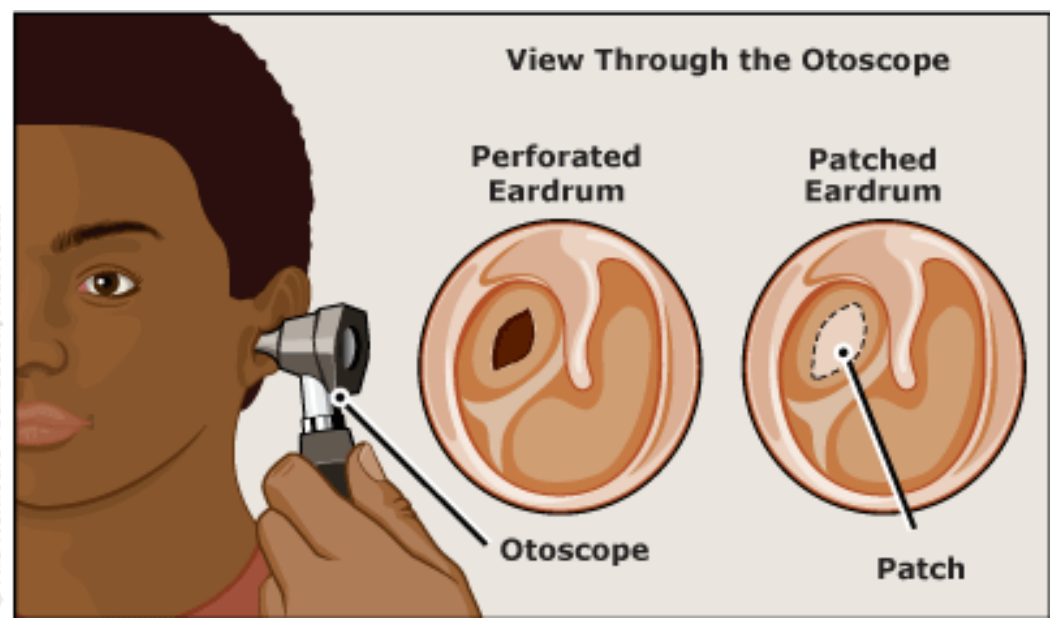

Figure 1: Tympanoplasty

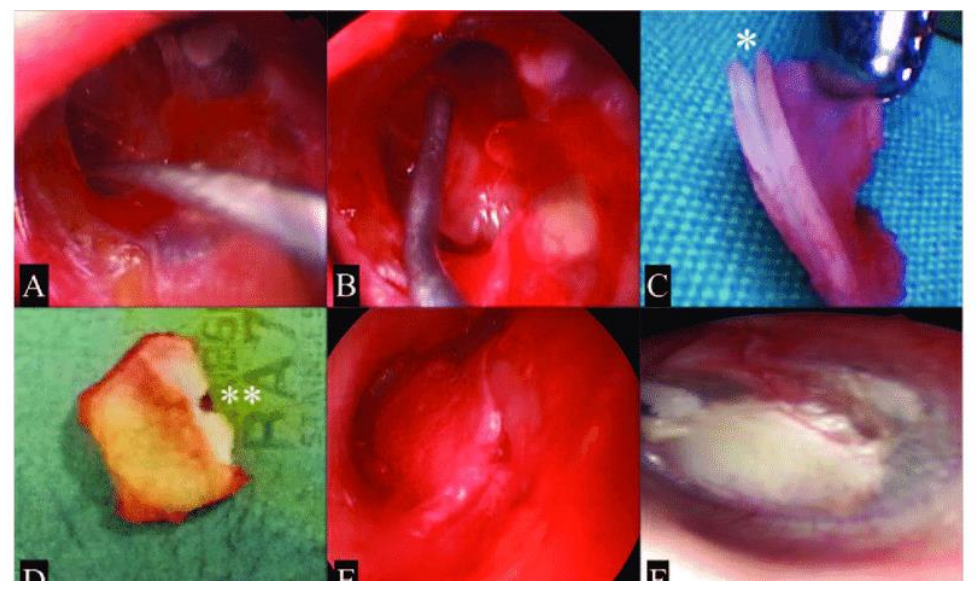

Figure 2: Procedure

The next stage was imprinting perforation for taking a dry gel foam piece and a mould of appropriate size [Fig.2]. A small, 11.5-centimeter incision, was then made across the tragus using 15 sized scalpel blade. An island of cartilage covered with perichondrium on both sides about $2 \mathrm{~mm}$ bigger than the freshened perforation was harvested.

The graft was held vertically between the thumb and forefinger and while rotating the graft, a 1 $\mathrm{mm}$ deep groove along the circumferential border of the cartilage disc was made using the same 15 sized scalpel blade allowing the cartilage flanges to spring open. The spreading of the two cartilage surfaces resembled the "Butterfly" and hence the name of the technique. [Fig.3] The skin incision was sutured up with 3-0 mersilk. 

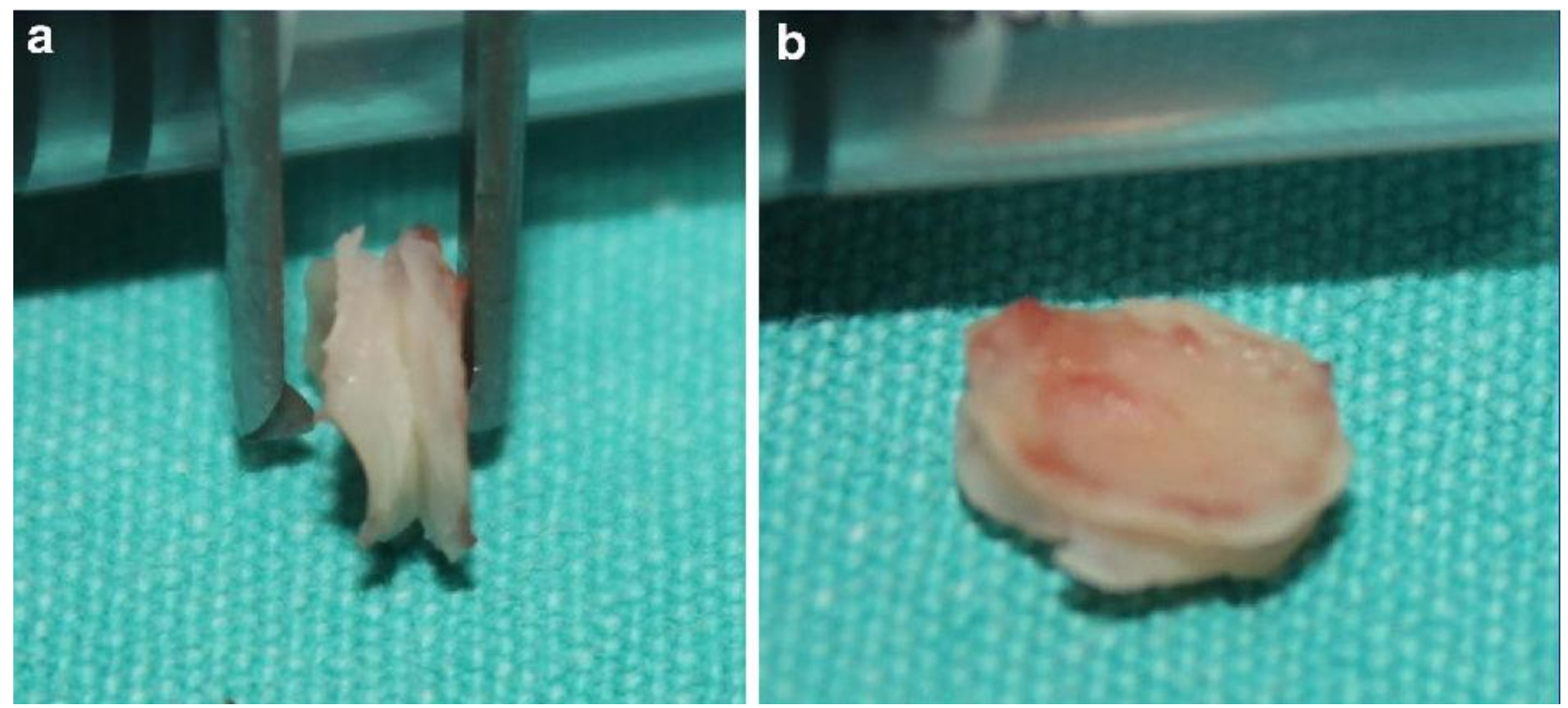

Figure 3: Butterfly technique of two cartilage

The graft was held with a crocodile forceps and was inserted transcanally and placed over the perforation. The groove in the cartilage was engaged with the anterior rim of the perforation so that the medial flange was medial to the tympanic membrane and the rest of the graft was manipulated into place so that the tympanic membrane sat in the groove of the cartilage graft very much like a grommet. To confirm the proper locking of the graft onto the perforation, it was gently moved with a ball probe [Fig.4]. On top we placed a thin gel foam layer soaked in antibiotic solution, and a cotton ball was used to seal the external auditory canal.

\section{RESULTS}

Demographic results indicate that there were 23 male and 7 female participated in the study. Average age was 32 years while age ranged from 16 to 55 years. Among these 30 patients, graft was taken up in 27 patients and for 3 patients, residual perforation with an overall success rate of $90 \%$. The anatomical success was assessed by otoscopy with graft well set in place. While functional success was analysed by PTA, which showed decrease in AirBone (A-B) gap in 25 patients $(83.3 \%$ ). This decrease in A-B gap was more than $20 \mathrm{~dB}$ (pre-op $\mathrm{AB}$ gap $=33.75 \mathrm{db}$, post op AB gap was $13.5 \mathrm{db}$ with $\mathrm{p}<0.05)$.

There were 5 patients which consisted of 3 failed cases as well, we found no gap improvement after tympanoplasty. A notable point is that all these 5 patients who experienced failure were in the age category of 51 to 55 years means higher age category.

Out of 3 patients in whom the graft was not taken up and there was persistent perforation, 2 patients had upper respiratory tract infection in the immediate post-operative period and there was discharge in external canal. In one patient graft was lying in external auditory canal. All patients were instructed to visit hospital for follows up every week during the first month and then on monthly basis for next six months. 


\section{Discussion}

Wullstein [2] introduced the idea of types and techniques related to the tympanoplasties. Since then several studies are conducted on this topic. The technique comes up with some variations such as different graft material such as conchal cartilage graft, tragal cartilage, tragal perichondrium, and temporalis fascia [5].

Tragal perichondrial graft and Temporalis fascia are closely matching with tympanic membrane and provide good results both functionally and anatomically [6]. For instance, study [7] showed that tragal perichondrium result was $80 \%$ and postoperative graft uptake rate with temporalis fascia was about $85 \%$. A success rate of $83 \%$ is reported based on homologus temporalis fascia in another study [8]. There are several studies which are based on tragal cartilage graft. For example, study by Sozen [9] showed that among 246 patients who participated in the study, comparison was made between temporalis muscle, tragal cartilage, and conchal cartilage and reported more than $80 \%$ success rate for all three techniques. In another study [10], 95\% success rate is reported with boomerang-shaped chondroperichondrial graft. Another study reported $93 \%$ success rate of graft takeup based on composite graft comprising perichondrium and peripheral ring of tragal cartilage [11].

New technique is introduced called Cartilage plug or butterfly cartilage tympanoplasty which is considered to be pioneered by Evaey in 1998. Based on this technique, the graft function as a membrane and its aim is to make the ear safe and improve hearing. An expert Ghanem [12] suggest that butterfly technique or Cartilage plug instantly locks of the graft provided by the tympanoplasty seems to be effective and butterfly edge decrease concerns about graft safety in terms of functional and anatomical displacement and lateralization due to the patient success with closure of perforation to make activities success rate of tympanic membrane the ear safe. The benefit is that it bypasses the needperforation closure with cartilage plugs. Testa [13] mentioned in study that this technique is associated with decreased morbidity and success rate of above $95 \%$.

\section{CONCLUSION}

The study was aimed to determine the clinical and audiometric success rate of new tragal cartilage plug or butterfly technique tympanoplasty. Based on the study of 30 patients with suitable inclusion criteria, the finding indicate that graft taken up was made by 27 patients out of 30 patients and we found overall success rate of $90 \%$. In sum, our conclusion is that tympanoplasty method is a suitable method and can be used as a good alternative treatment for repairing tympanic membrane perforations.

\section{References}

1. Zoellner, F. (1955). The principles of plastic surgery of the sound-conducting apparatus. The Journal of Laryngology \& Otology, 69, 567-569.

2. Wullstein, H.L. (1952). Functional operations in the middle ear with split-thickness skin graft. Arch Otorhinolaryngol,161, 422-435. 
3. Rizer, F.M. (1997). Overlay versus underlay tympanoplasty. part 11: the study. Laryngoscope, 107, 115-118.

4. Eavey, R.D. (1998). Inlay tympanoplasty; cartilage butterfly technique. Laryngoscope, 108, 657-661.

5. Eviatar, A. (1978). Tragal perichondrium and cartilage in reconstructive ear surgery. Laryngoscope, 88(S11), 1-23.

6. Dhabolkar, J., Vora, K., Sikdar, A. (2007). Comparative study of underlay tympanoplasty with temporalis fascia and tragal perichondrium. Indian Journal of Otolaryngology Head and Neck Surgery, 59(2), 116-119.

7. Parida, P.K., Nochikatil, S.K. (2011). A Comparative Study of Temporalis Fascia Graft and Vein Graft in Myringoplasty. Indian Journal of Otolaryngology Head and Neck Surgery, 0543-0544.

8. Ahad, S.A. (1986). Myringoplasty using homologous temporalis fascia. Indian Journal of Otology, 33, 28-29.

9. Sözen, E., Orhan, Uçal, Y., Tansuker, H.D., Uslu, Coşkun, B., Yasemin, Korkut, A., Dadaş, B.(2012). Is the tragal cartilage necessary for type 1 tympanoplasties? Journal of Craniofac Surgery, 23, e280-283.

10. Dündar, R., Soy, F.K., Kulduk, E., Muluk, N.B., Cingi, C. (2014). A new grafting technique for tympanoplasty: Tympanoplasty with a boomerang-shaped chondroperichondrial graft (TwBSCPG). European Archives of Oto-Rhino-Laryngology, 271, 2687-2694

11. Debasish, G., Arindam, D., Sayan, H., Arunabha, S. (2018). Maximising graft take-up in type 1 tympanoplasty using peripheral cartilage ring and perichondrium. Indian Journal of Otolaryngology Head and Neck Surgery, 70, 290-294.

12. Ghanem, M.A., Monroy, A., Alizade, F.S., Nicolau, Y., Eavey, R.D. (2006). Butterfly cartilage graft inlay tympanoplasty for large perforations. Laryngoscope, 116, 1813-1816.

13. Testa, J.R.G., Teixeira, M.S., Ribeiro, K.M., Pizarro, G.U., Millas, I. (2002). Cartilagem tragal com pericôndrio em timpanoplastias. Revista Brasileira de Otorrinolaringologia (Brazilian Journal of Otolaryngology).68(5), 920-925.

14. Lubianca-Neto, J.F. (2000). Inlay butterfly cartilage tympanoplasty (Eavey technique) modified for adults. Otolaryngol Head Neck Surg, 123(4), 492-494. 